\title{
Novel role of microRNA-126 in digestive system cancers: From bench to bedside (Review)
}

\author{
MINGLI HU, SHENGWEI XIONG, QIAOFENG CHEN, SHIXUAN ZHU and XIAODONG ZHOU \\ Department of Gastroenterology, The First Affiliated Hospital of Nanchang University, \\ Nanchang, Jiangxi 330000, P.R. China
}

Received March 21, 2018; Accepted September 28, 2018

DOI: $10.3892 / 01.2018 .9639$

\begin{abstract}
MicroRNAs (miRNAs) are ubiquitously expressed, small, non-coding RNAs that regulate the expression of approximately $30 \%$ of the human genes at the post-transcriptional level. miRNAs have emerged as crucial modulators in the initiation and progression of various diseases, including numerous cancer types. The high incidence rate of cancer and the large number of cancer-associated cases of mortality are mostly due to a lack of effective treatments and biomarkers for early diagnosis. Therefore there is an urgent requirement to further understand the underlying mechanisms of tumorigenesis. MicroRNA-126 (miR-126) is significantly downregulated in a number of tumor types and is commonly identified as a tumor suppressor in digestive system cancers (DSCs). miR-126 downregulates various oncogenes, including disintegrin and metalloproteinase domain-containing protein 9 , v-crk sarcoma virus CT10 oncogene homolog and phosphoinositide-3-kinase regulatory subunit 2 . These genes are involved in a number of tumor-associated signaling pathways, including angiogenesis, epithelial-mensenchymal transition and metastasis pathways. The aim of the current review was to summarize the role of miR-126 in DSCs, in terms of its dysregulation, target genes and associated signaling pathways. In addition, the current review has discussed the potential clinical application of miR-126 as a biomarker and therapeutic target for DSCs.
\end{abstract}

\section{Contents}

1. Introduction

2. Structure and function of $\mathrm{miR}-126$

3. Aberrant expression of miR-126 in DSCs

Correspondence to: Professor Xiaodong Zhou, Department of Gastroenterology, The First Affiliated Hospital of Nanchang University, 17 Yongwaizheng Road, Nanchang, Jiangxi 330000, P.R. China

E-mail: yfyzxd@163.com

Key words: microRNA-126, digestive system cancers, target genes, signaling pathways, clinical applications
4. Targets of miR-126 in DSCs

5. Signaling cascades modulated by miR-126 in DSCs

6. miR-126 serves as a useful biomarker in DSCs

7. Therapeutic implications of miR-126 in DSCs

8. Conclusions

\section{Introduction}

Cancer is a major global public health problem and a leading cause of mortality. Digestive system cancer types (DSCs) are the most common malignant tumors affecting the organs and glands of the digestive tract. DSCs include esophageal, stomach, colon, rectum, liver, gallbladder and pancreatic carcinomas (1). Colorectal cancer (CRC) is the third most commonly diagnosed cancer type, whilst liver cancer and gastric cancer (GC) were second and third to lung cancer as the most frequent causes of cancer-associated cases of mortality worldwide in 2012 (2). Pancreatic cancer (PC) is usually detected at an advanced stage with extensive invasion and lymphatic metastasis, when the estimated 5-year survival rate is well below 5\% (3). Early detection of DSCs is limited by the absence of specific symptoms prior to metastasis, which leads to poor prognosis. Therefore, it is of great importance to identify novel predictive and prognostic biomarkers, including genetic and epigenetic alterations at early stages that can detect and monitor tumor dynamics.

A number of studies have identified that microRNAs (miRNAs) are aberrantly expressed in human cancer types due to genomic or epigenetic alterations $(4,5)$. miRNAs are a class of single-stranded, small RNAs approximately 22 nucleotides in length. miRNAs serve as essential post-transcriptional regulators by binding to the 3'-untranslated region (3'-UTR), 5'-UTR or coding sequences of target mRNAs (6). Notably, miRNAs are thought to modulate almost $30 \%$ of human genes $(5,7)$. The extensive regulatory functions of miRNAs are not only associated with developmental timing, cell proliferation and apoptosis, but also play a critical role in oncogenesis and tumor suppression (7). Numerous miRNAs have been demonstrated to interact with their target genes and tumor-associated pathways through subtly regulated networks $(7,8)$. The current review summarizes the latest findings regarding the crucial roles of miR-126 in major DSCs. Furthermore, the potential clinical value of miR-126 as a novel diagnostic and prognostic biomarker 
and therapeutic target in DSCs is discussed. The current review aims to improve understanding regarding the significance of the miR-126 regulatory mechanisms in human cancer types.

\section{Structure and function of miR-126}

miR-126 and its passenger strand, miR-126*, are two endothelial cell-specific miRNAs that mediate angiogenesis (9). Both miR-126 and miR126* are encoded by the epidermal growth factor-like domain 7 (EGFL7) gene (10). miR-126 usually refers to the 3 'region of the transcript, also termed miR-126-3p, located within the 7th intron of EGFL7. Whereas, miR-126" refers to the 5 ' region of the transcript, also termed miR-123 or miR-126-5p, which binds to the main miR-126 transcript at the stem loop structure of the precursor miRNA $(10,11)$ (Fig. 1). EGFL7 is located on chromosome 9 in humans and encodes an endothelial cell-derived factor involved in the repression of smooth muscle cell migration and the regulation of angiogenesis $(12,13)$. EGFL7 is highly expressed in the vasculature during embryonic development and at a relatively lower level in adult blood vessels $(13,14)$. However, an aberrant upregulation of EGFL7 can be observed during pathological angiogenesis in malignant tumors (15).

To the best of our knowledge, miR-126 is the only miRNA with specific expression in the endothelial cell lineage and hematopoietic progenitor cells (11). Targeted deletion of miR-126 results in a loss of vascular integrity, which leads to ruptured vessels and impaired endothelial cell migration $(9,10)$. Functionally, miR-126 is significantly associated with angiogenesis and inflammation. miR-126 suppresses sprouty-related EVH1 domain-containing protein 1 (SPRED1) and phosphoinositide-3-kinase regulatory subunit 2 (PI3KR2), both of which inhibit receptor tyrosine kinase-induced signaling via the mitogen-activated protein kinase (MAPK) and phosphinositide-3-kinase (PI3K) signaling pathways, thereby promoting vascular endothelial growth factor (VEGF) signaling and angiogenesis (9). Although miR-126 expression is usually altered in parallel with the expression of EGFL7 protein, miR-126 can downregulate EGFL7, leading to reduced angiogenesis and cell proliferation via a negative feedback loop mechanism $(9,16)$. In addition, endogenous miR-126 has been revealed to inhibit the expression of vascular cell adhesion molecule 1 (VCAM-1) and prevent leukocyte adhesion and infiltration to further control vascular inflammation (17). Furthermore, miR-126 can suppress inflammation and reactive oxygen species production in endothelial cells under hyperglycemic conditions by post-transcriptionally inhibiting the expression of high-mobility group box 1 (18). The functional properties of miR-126* are less well understood. The significant role of miR-126 as a tumor suppressor involved in various signaling cascades has been demonstrated in previous studies $(11,19)$. Aberrant expression of miR-126 has been identified in numerous human cancer types, including melanoma, osteosarcoma, leukemia and carcinomas of the digestive system, endocrine glands, urogenital system and respiratory system (20).

\section{Aberrant expression of miR-126 in DSCs}

Numerous miRNAs have been revealed to be abnormally expressed in multiple cancer types (21). Both miR-126 and
miR-126" are highly expressed in endothelial cells in vivo (9). In addition, miR-126 is overexpressed in highly vascularized organs, including the heart, liver and lungs $(22,23)$. Table I lists previous studies that have identified that miR-126 expression is significantly decreased in human DSC tissues compared with adjacent non-cancerous tissues (24-58). Notably, miR-126 is involved in angiogenesis and has significantly higher expression levels in hepatocellular carcinoma (HCC) tissues treated with transcatheter arterial chemoembolization (TACE) and surgery, compared with tissues only subjected to surgical resection (53). Another study identified that HCC tissues exhibit an elevated level of miR-126 compared with adjacent non-cancerous tissues, although miR-126 may inhibit tumor angiogenesis and proliferation (16). In addition, miR-126 is aberrantly expressed in certain GC tissues $(33,38)$.

miR-126 expression levels are downregulated in almost all established esophageal cancer (EC), CRC, HCC and PC cell lines and certain GC cell lines (Table I). Restoring or upregulating miR-126 expression can inhibit cancer cell proliferation, migration and invasion in vitro, indicating a potential tumor suppressive function or miR-126 in DSCs $(19,49,51,56)$. However, Otsubo et al (33) have revealed that five GC cell lines (HSC43, HSC58, NUGC3, NUGC4 and GCIY) exhibit high levels of miR-126. Similarly, miR-126 has also been identified to be significantly upregulated in the AGS, HGC-27, BGC-823, SGC-7901 and MKN-7 cell lines of GC (38), indicating miR-126 may exhibit a potential oncogenic role in GC (33).

Genetic and epigenetic changes lead to alterations in tumor-associated gene expression. Aberrant changes in gene sequence, dicer abundance and epigenetic modifications, including DNA methylation, histone modifications and nucleosome positioning, predominantly account for miR-126 dysregulation in cancer (20). For example, the downregulation of miR-126 in CRC is partly due to promoter methylation of its host gene EGFL7 (45). Pagano et al (59) have identified the existence of epigenetic-miRNA loops in hematopoietic cells, which can either modulate or be modulated by epigenetic factors and therefore regulate the gene expression profile. Subsequently, Liu et al (26) identified a DNA (cytosine-5)-methyltransferase 1 (DNMT1)-miR-126 epigenetic circuit in esophageal squamous cell carcinoma (ESCC) cells. DNMT1 is aberrantly upregulated in ESCC cells, which leads to the hypermethylation of EGFL7 and downregulation of miR-126, whilst upregulation of miR-126 markedly reduces the expression of DNMT1 (26). In addition, overexpressed HOX antisense intergenic RNA (HOTAIR) in GC serves as a competing endogenous RNA and directly associates with miR-126 to dysregulate the expression of miR-126 (60). Finally, the tumor suppressor nasopharyngeal carcinoma-associated gene 6 has been revealed to upregulate miR-126 in colon cancer (61).

\section{Targets of miR-126 in DSCs}

miRNAs modulate their target gene expression by binding to the 3'-UTR of the corresponding mRNA. Numerous studies have identified that miR-126 regulates key processes in different cancer types by targeting various genes, including insulin receptor substrate $1, \mathrm{v}$-crk sarcoma virus CT10 oncogene homolog (CRK), CXC chemokine 


\section{Chromosome 9}

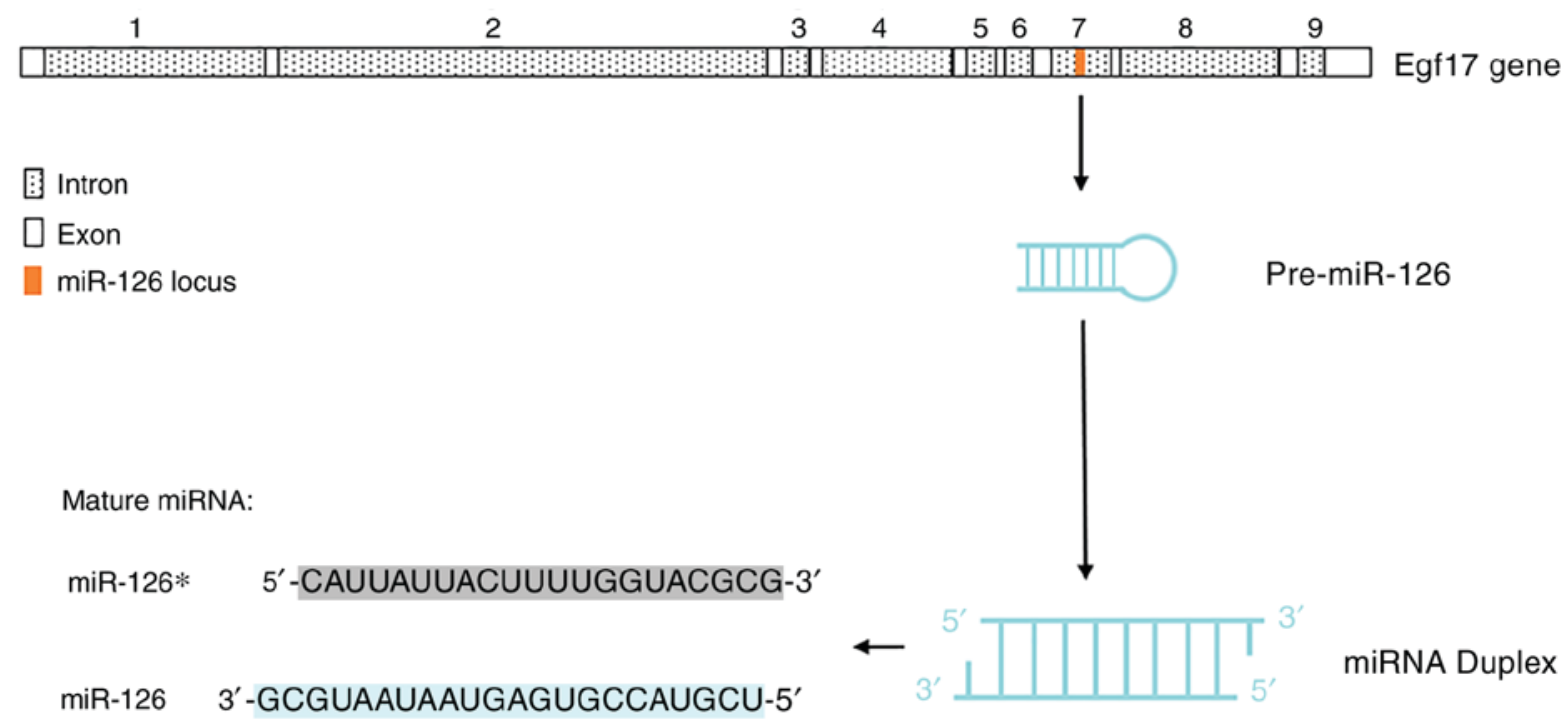

Figure 1. Origin and structure of miR-126/miR-126*. The EGFL7 gene consists of nine introns located on human chromosome 9. A pre-miR structure is located within intron 7 of the EGFL7 gene from which miR-126 and miR-126* originate. miR or miRNA, microRNA; *, passenger strand; EGFL7, epidermal growth factor-like domain 7.

receptor type 4 (CXCR4), disintegrin and metalloproteinase domain-containing protein 9 (ADAM9) and sex-determining region Y-box 2 (SOX2). As presented in Table I, the majority of these target genes are overexpressed in DSCs and function as oncogenes involved in cell proliferation, cell cycle, cell senescence, differentiation, apoptosis and metastasis at both genetic and epigenetic levels. Therefore, miR-126 is an effective regulator of tumorigenesis and progression. VCAM-1 and PI3KR2 are associated with the anti-inflammatory and anti-neoplastic functions of pomegranate polyphenols in colon cancer (42). Golgi phosphoprotein 3 (GOLPH3), the target of miR-126 in ESCC, contributes to tumorigenicity and tumor cell proliferation $(27,62)$. Several studies have demonstrated that miR-126 targets CXCR4 and suppresses its expression, which inhibits tumor cell proliferation, migration, invasion and cell apoptosis, and arrests the cell cycle at the $\mathrm{G}_{0} / \mathrm{G}_{1}$ transition $(46,47)$. VEGF overexpression and neo-angiogenesis in $\mathrm{CRC}$ is associated with miR-126 downregulation (45). The oncogenic targets of miR-126 associated with HCC include the pro-angiogenic PI3KR2 (51) and EGFL7 $(16,54)$, in addition to the pro-metastatic low-density lipoprotein receptor-related protein 6 (LRP6) (51). Abnormally high expression of EGFL7 in $\mathrm{HCC}$ is also associated with increased proliferation and decreased apoptosis in HCC cells (54). ADAM9 overexpression in PC (61), regulator of $G$ protein signaling 3 (RGS3) overexpression in GC $(41,63)$ and aberrantly high levels of SOX2 in pancreatic ductal adenocarcinoma (PDAC) (64) are all positively associated with cellular migration, invasion and epithelial-mesenchymal transition (EMT) (56).

The dysregulation of these targets not only promotes the initiation and development of DSCs, but may also be useful as novel markers for diagnosing, monitoring and predicting the prognosis of DSCs. As targets of miR-126 in GC, CRK and CRK-like (CRKL) have been revealed to facilitate adhesion, invasion and migration of cancer cells. Furthermore, overexpression of CRK and CRKL has been associated with more aggressive clinicopathological features, including a larger tumor size, a higher number of lymph node metastases, deeper local invasion and higher tumor-node-metastasis (TNM) staging $(19,34)$. Overexpression of GOLPH3 may be associated with a poor outcome for patients with ESCC (62). Similarly, the expression level of ADAM9 is a confirmed prognostic factor for HCC (55) and a VEGF polymorphism is associated with higher susceptibility to GC (65). In summary, the aforementioned markers may assist in screening populations at high risk and preventing progression of tumorigenesis.

While the anti-tumor function of miR-126 is well established and is known to depend on targeting and dysregulating the aforementioned oncogenes, there are certain reports that suggest miR-126 serves an oncogenic role in DSCs by targeting certain tumor-suppressor genes. Cell adhesion molecule 1 (CADM1) and SOX2 are suppressed upon miR-126 overexpression in GC cells, leading to carcinogenesis, migration and invasion $(33,38)$. Furthermore, a pro-angiogenic role of miR-126 has been identified in HCC tissues, with SPRED1 inhibition as the underlying mechanism (53). Hansen et al (44) also revealed that a higher expression of miR-126 in CRC tissues is associated with increased expression of VEGFR-2 and a denser microvessel density (MVD).

The targets of miR-126 in DSCs can also be negatively modulated by miR-126 in other tumors. For instance, CRK is targeted by miR-126 in non-small cell lung cancer cells (66) and solute carrier family 7 member 5 has been identified as an miR-126 target in colon cancer and thyroid cancer $(50,67)$. In addition, miR-126 can regulate the same or different targets in DSCs by cooperating with other miRNAs. For instance, miR-145 exerts its role of inhibiting tumor growth in colon cancer by targeting and regulating IRS-1 (68). Additionally, miR-126 and miR-34a can synergistically exert a tumor suppressive effect by targeting VEGF-A, SOX2, cyclin D1, E2F1 and B-cell lymphoma 2 in pancreatic adenocarcinoma (PAC) (58). 
Table I. Aberrant expression, target genes and direct functions of miR-126 in various types of digestive system cancer.

A, Esophageal cancer

\begin{tabular}{|c|c|c|c|c|}
\hline Expression & Sample(s) & Target gene(s) & Direct function(s) & (Refs.) \\
\hline Down & Tissues & - & - & $(24,25)$ \\
\hline Down & $\begin{array}{l}\text { Tissues/cell } \\
\text { lines }\end{array}$ & $\begin{array}{l}\text { DNMT1 and } \\
\text { ADAM9 }\end{array}$ & $\begin{array}{c}\text { Forming DNMT1-miR-126 } \\
\text { loop and suppressing ADAM9 expression }\end{array}$ & (26) \\
\hline Down & $\begin{array}{l}\text { Tissues/cell } \\
\text { lines }\end{array}$ & $\begin{array}{l}\text { IRS-1 and } \\
\text { GOLPH3 }\end{array}$ & $\begin{array}{l}\text { Downregulating the expression of IRS-1 } \\
\text { and GOLPH3 protein }\end{array}$ & (27) \\
\hline Down & $\begin{array}{l}\text { Tissues/cell } \\
\text { lines }\end{array}$ & SOX2 & $\begin{array}{l}\text { Inhibiting SOX2 expression by } \\
\text { targeting its mRNA 3'-UTR }\end{array}$ & (28) \\
\hline Down & $\begin{array}{l}\text { Tissues/cell } \\
\text { lines }\end{array}$ & PI3KR2 & $\begin{array}{l}\text { Inhibiting PI3K/AKT signaling } \\
\text { pathway }\end{array}$ & (29) \\
\hline Down & $\begin{array}{l}\text { Tissues/cell } \\
\text { lines }\end{array}$ & VEGF-A & $\begin{array}{c}\text { Negatively regulating VEGF-A } \\
\text { expression }\end{array}$ & (30) \\
\hline
\end{tabular}

B, Gastric cancer

\begin{tabular}{|c|c|c|c|c|}
\hline Expression & Sample(s) & Target gene(s) & Direct function(s) & (Refs.) \\
\hline Down & $\begin{array}{l}\text { Tissues/cell } \\
\text { lines }\end{array}$ & CRK & $\begin{array}{l}\text { Downregulating the expression } \\
\text { of CRK }\end{array}$ & $(19,31,32)$ \\
\hline $\mathrm{Up} /$ down $^{\mathrm{a}}$ & Cell lines & SOX2 & $\begin{array}{l}\text { Repressing SOX2 expression by } \\
\text { targeting its mRNA } 3 \text { '-UTR }\end{array}$ & (33) \\
\hline Down & $\begin{array}{l}\text { Tissues/cell } \\
\text { lines }\end{array}$ & CRKL & $\begin{array}{c}\text { Negatively regulating CRKL expression } \\
\text { by targeting its mRNA 3'-UTR }\end{array}$ & (34) \\
\hline Down & $\begin{array}{l}\text { Tissues/cell } \\
\text { lines }\end{array}$ & VEGF-A & $\begin{array}{l}\text { Reducing the expression of VEGF-A } \\
\text { by binding to its mRNA 3'-UTR }\end{array}$ & $(35)$ \\
\hline Down & $\begin{array}{l}\text { Tissues/cell } \\
\text { lines }\end{array}$ & $\begin{array}{l}\text { PLK2, PI3KR2 } \\
\text { and CRK }\end{array}$ & $\begin{array}{l}\text { Synergistically reducing the expression } \\
\text { of PLK2, PI3KR2 and CRK }\end{array}$ & (36) \\
\hline Down & $\begin{array}{l}\text { Tissues/cell } \\
\text { lines }\end{array}$ & LAT-1 & $\begin{array}{l}\text { Negatively regulating the expression } \\
\text { of LAT-1 }\end{array}$ & (37) \\
\hline Up & Cell lines & CADM1 & $\begin{array}{c}\text { Downregulating CADM1 expression } \\
\text { by targeting its mRNA 3'-UTR }\end{array}$ & (38) \\
\hline Down & Cell lines & $\mathrm{EZH} 2$ & $\begin{array}{l}\text { Decreasing EZH2 expression to } \\
\text { regulate chemotherapy resistant }\end{array}$ & (39) \\
\hline Down & Cell lines & ADAM9 & $\begin{array}{l}\text { Downregulating ADAM9 expression } \\
\text { by binding to its mRNA 3'-UTR }\end{array}$ & $(40)$ \\
\hline Down & $\begin{array}{l}\text { Tissues/cell } \\
\text { lines }\end{array}$ & RGS3 & $\begin{array}{l}\text { Post-transcriptionally downregulating } \\
\text { the expression of RGS3 }\end{array}$ & (41) \\
\hline
\end{tabular}

C, Colorectal cancer

\begin{tabular}{|c|c|c|c|c|}
\hline Expression & Sample(s) & Target gene(s) & Direct function(s) & (Refs.) \\
\hline Down & Cell lines & $\mathrm{p} 85 \beta(\mathrm{PI} 3 \mathrm{KR} 2)$ & $\begin{array}{l}\text { Reducing the level of } \mathrm{p} 85 \beta \\
\text { and phospho-AKT }\end{array}$ & $(42,43)$ \\
\hline- & Cell lines & VCAM-1 & $\begin{array}{l}\text { The expression level of miR-126 } \\
\text { inversely correlates with VCAM-1 }\end{array}$ & $(42)$ \\
\hline Down & Tissues & VEGFR-2 & $\begin{array}{c}\text { Elevated miR-126 is associated with } \\
\text { high VEGFR-2 expression }\end{array}$ & (44) \\
\hline Down & $\begin{array}{l}\text { Tissues/cell } \\
\text { lines }\end{array}$ & VEGF & $\begin{array}{l}\text { Suppressing the expression of VEGF } \\
\text { by binding to its mRNA 3'-UTR }\end{array}$ & $(45)$ \\
\hline
\end{tabular}


Table I. Continued.

\begin{tabular}{|c|c|c|c|c|}
\hline Expression & Sample(s) & Target gene(s) & Direct function(s) & (Refs.) \\
\hline Down & $\begin{array}{l}\text { Tissues/cell } \\
\text { lines }\end{array}$ & CXCR4 & $\begin{array}{l}\text { Negatively regulating CXCR4 } \\
\text { expression }\end{array}$ & $(46,47)$ \\
\hline Down & $\begin{array}{l}\text { Tissues/cell } \\
\text { lines }\end{array}$ & RhoA/ROCK & $\begin{array}{c}\text { Inhibiting RhoA/ROCK signaling } \\
\text { pathway }\end{array}$ & $(46,48)$ \\
\hline Down & Cell lines & IRS-1 & $\begin{array}{l}\text { Inhibiting IRS-1 expression by binding } \\
\text { to its mRNA } 3 \text { '-UTR }\end{array}$ & $(49)$ \\
\hline Down & $\begin{array}{l}\text { Tissues/cell } \\
\text { lines }\end{array}$ & $\begin{array}{l}\text { IRS-1, SLC7A5 } \\
\text { and TOM1 }\end{array}$ & $\begin{array}{l}\text { Reducing the expression of IRS1, } \\
\text { SLC7A5 and TOM1 }\end{array}$ & $(50)$ \\
\hline \multicolumn{5}{|c|}{ D, Hepatocellular carcinoma } \\
\hline Expression & Sample(s) & Target gene(s) & Direct function(s) & (Refs.) \\
\hline Down & $\begin{array}{l}\text { Tissues/cell } \\
\text { lines }\end{array}$ & $\begin{array}{l}\text { LRP6 and } \\
\text { PI3KR2 }\end{array}$ & $\begin{array}{l}\text { Negatively regulating LRP6 and } \\
\text { PI3KR2/phospho-AKT expression }\end{array}$ & $(51)$ \\
\hline Down & Cell lines & SOX2 & $\begin{array}{l}\text { Inhibiting SOX2 expression by binding } \\
\text { to its mRNA } 3 \text { '-UTR }\end{array}$ & $(52)$ \\
\hline Down & Tissues & $\begin{array}{l}\text { SPRED1 and } \\
\text { VEGF }\end{array}$ & $\begin{array}{c}\text { Inhibiting the expression of SPRED1 } \\
\text { and VEGF }\end{array}$ & $(53)$ \\
\hline Down & $\begin{array}{l}\text { Tissues/cell } \\
\text { lines }\end{array}$ & EGFL7 & $\begin{array}{l}\text { Suppressing the expression of } \\
\text { EGFL7 }\end{array}$ & $(54)$ \\
\hline Up & Tissues & EGFL 7 & $\begin{array}{l}\text { Downregulating EGFL7 expression to } \\
\text { inhibit proliferation and angiogenesis }\end{array}$ & (16) \\
\hline Down & $\begin{array}{l}\text { Tissues/cell } \\
\text { lines }\end{array}$ & ADAM9 & $\begin{array}{l}\text { Downregulating the expression of } \\
\text { ADAM9 }\end{array}$ & $(55)$ \\
\hline
\end{tabular}

E, Pancreatic cancer

\begin{tabular}{|c|c|c|c|c|}
\hline Expression & Sample(s) & Target gene(s) & Direct function(s) & (Refs.) \\
\hline own & $\begin{array}{l}\text { Tissues/cell } \\
\text { lines }\end{array}$ & ADAM9 & $\begin{array}{l}\text { Inhibiting ADAM9 expression by } \\
\text { binding to its mRNA 3'-UTR }\end{array}$ & (56) \\
\hline Down & $\begin{array}{l}\text { Tissues/cell } \\
\text { lines }\end{array}$ & $\begin{array}{l}\text { KRAS and } \\
\text { CRK }\end{array}$ & $\begin{array}{c}\text { Reducing the expression of KRAS } \\
\text { and CRK }\end{array}$ & $(57)$ \\
\hline Down & $\begin{array}{l}\text { Tissues/cell } \\
\text { lines }\end{array}$ & $\begin{array}{c}\text { VEGF-A } \\
\text { and SOX2 }\end{array}$ & $\begin{array}{c}\text { Downregulating the expression of } \\
\text { VEGF-A and SOX2 }\end{array}$ & (58) \\
\hline \multicolumn{5}{|c|}{$\begin{array}{l}\text { an the particular study, it was reported that among the } 10 \text { gastric cancer cell lines studied, } 4 \text { exhibited high miR-126 expression, wherea } \\
5 \text { exhibited low expression. miR-126, microRNA-126; DNMT1, DNA methyltransferase 1; ADAM9, disintegrin and metalloproteinase } \\
\text { domain-containing protein 9; IRS-1, insulin receptor substrate 1; GOLPH3, Golgi phosphoprotein 3; SOX2, sex-determining region Y-box } 2 \\
\text { UTR, untranslated region; PI3KR2, phosphoinositide-3-kinase regulatory subunit; PI3K, phosphoinositide-3-kinase; VEGF-A, vascular endo } \\
\text { thelial growth factor A; CRK, v-crk sarcoma virus CT10 oncogene homolog; CRKL, v-crk avian sarcoma virus CT10 oncogene homolog-like } \\
\text { PLK2, polo-like kinase 2; LAT-1, l-type amino-acid transporter 1; CADM1, cell adhesion molecule 1; EZH2, enhancer of zeste homolog } 2 \\
\text { RGS3, regulator of G-protein signaling 3; VCAM-1, vascular cell adhesion molecule 1; VEGFR-2, vascular endothelial growth facto } \\
\text { receptor 2; CXCR4, CXC chemokine receptor type 4; RhoA, ras homology gene family, member A; ROCK, Rho-associated protein kinase } \\
\text { SLC7A5, solute carrier family } 7 \text { member 5; TOM1, tobamovirus multiplication 1; LRP6, low-density lipoprotein receptor-related protein } 6 \\
\text { SPRED1, sprouty-related EVH1 domain-containing protein 1; EGFL7, epidermal growth factor-like domain } 7 \text {. }\end{array}$} \\
\hline
\end{tabular}

Notably, several targets of miR-126 in DSCs are exclusively regulated by miR-126 in specific cancer types. Studies indicate that PI3KR2 and VEGF-A are regulated by miR-126 solely or together in $\operatorname{EC}(29,30), \operatorname{GC}(35,36), \mathrm{CRC}(42), \mathrm{HCC}(51)$ and
PAC (58). It has also been demonstrated that miR-126 targets IRS-1 only in ESCC (27) and CRC (50). KRAS has been confirmed as a target of miR-126 in PDAC and in contrast to the typical miRNA-target gene interaction, miR-126 binds 


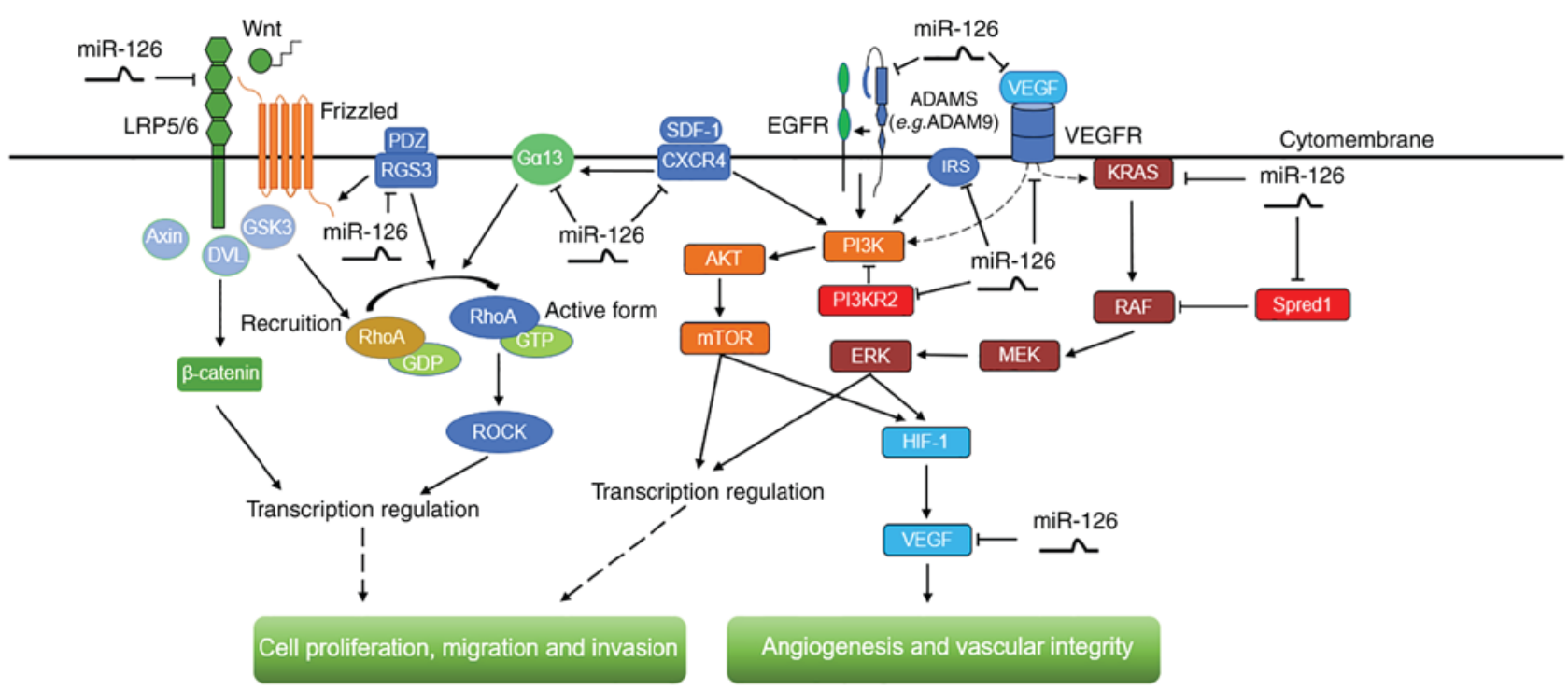

Figure 2. The signaling pathways, including Ras/ERK, PI3K/AKT/mTOR, ADAM9/EGFR/AKT, RhoA/ROCK and Wnt/ $\beta$-catenin, modulated by miR-126 in digestive system cancer types. These signaling cascades are involved in the regulation of angiogenesis and vascular integrity, as well as cell proliferation, migration and invasion. miR-126, microRNA-126; ERK, extracellular signal-regulated kinase; PI3K, phosphatidylinositol-3-kinase; mTOR, mammalian target of rapamycin; ADAM9, disintegrin and metalloproteinase domain-containing protein 9; EGFR, epidermal growth factor receptor; RhoA, ras homology gene family, member A; ROCK, Rho-associated protein kinase; LRP5/6, low density lipoprotein receptor related protein 5/6; GSK3, glycogen synthase kinase 3; DVL, dishevelled; RGS3, regulator of G protein signaling 3; G 13 , G protein $\alpha 13$; GTP, guanosine 5'-triphosphate; GDP, guanosine 5'-diphosphate; SDF-1, stromal cell-derived factor-1; CXCR4, CXC chemokine receptor type 4; PI3KR2, phosphoinositide-3-kinase regulatory subunit 2; IRS-1, insulin receptor substrate 1; VEGF, vascular endothelial growth factor; VEGFR, VEGF receptor; SPRED1, sprouty-related EVH1 domain-containing protein 1; MEK, mitogen-activated protein kinase; HIF1, hypoxia-inducible factor 1.

to KRAS at an uncommon site in its 3'-UTR (57). However, KRAS expression is not influenced by miR-126 in CRC (69). Furthermore, certain genes that are targeted by miR-126 in several DSCs serve different roles in different cancer types. SOX2, an inhibitor of GC growth (70), promotes tumor cell proliferation and invasion in EC (28). A feedback regulatory loop may also exist between miR-126 and its target genes, as identified with DNMT1 in ESCC, which increases the intricacy of the regulation network of the miRNA (26).

\section{Signaling cascades modulated by miR-126 in DSCs}

In addition to numerous cancer-associated genes, miR-126 also interacts with the signaling pathways involved in DSCs. Various signaling cascades involved in the regulation of angiogenesis and vascular integrity, as well as cell proliferation, migration and invasion are modulated by miR-126 (Fig. 2).

miR-126 regulates the expression of VEGFR-2 and VEGF in DSCs via the MAPK/ERK and PI3K/AKT pathways $(44,45)$, and can impede the growth of cancer cells by targeting p85 $\beta$ (also termed PI3KR2), leading to decreased levels of phosphorylated AKT, the active form of the kinase (29). AKT phosphorylates a wide range of proteins involved in cell survival, motility and proliferation (71). Myelin transcription factor 1 , which is phosphorylated by AKT to modulate the G2/M-phase transition (72), is also upregulated by miR-126 (29). Zhou et al (49) identified that miR-126 suppresses the proliferation, migration, invasion and cell cycle progression of cancer cells by targeting IRS-1 via the AKT and ERK1/2 signaling pathways. The anti-angiogenic role of miR-126 in cancer tissues is exerted by targeting VEGF-A, possibly via the MAPK/ERK and AKT/mammalian target of rapamycin (mTOR) signaling pathways $(16,35,53,54)$, which reduces the MVD in cancer tissues (51). In addition, miR-126 exhibits a suppressive role in the proliferation, apoptosis and angiogenesis of tumor cells and tissues by targeting EGFL7, through the inactivation of the ERK signaling pathway (73). HOTAIR, a long non-coding RNA that is increased in GC and is responsible for drug-resistance, potentially acts by binding to and dysregulating miR-126, leading to the upregulation of miR126-targeted oncogenes, including VEGF-A and PI3KR2, and activation of the PI3K/AKT/multidrug resistance-associated protein 1 pathway (60).

Furthermore, miR-126 inhibits the activity and expression of the Ras homology gene family, member A (RhoA)/Rho-associated protein kinase (ROCK) signaling pathway mediators that are aberrantly upregulated in cancer cells. The expression of these mediators positively correlates with clinical stage and lymph node metastasis but negatively correlates with overall survival of patients with cancer (46). CXCR4 is a putative mediator between miR-126 and the RhoA/ROCK signaling pathway $(46,48)$. It has been identified that miR-126 exerts a tumor suppressive effect by targeting CXCR4 and involving the stromal cell-derived factor 1/CXCR4 axis, which possibly promotes MAPK p42/44 phosphorylation and activates the PI3K/AKT pathway $(74,75)$. Furthermore, miR-126 was revealed to be a tumor suppressor in CRC through the AKT and ERK1/2 signaling pathways, by dysregulating CXCR4 (47). Additionally, Yuan et al (46) observed that CXCR4 could prevent the inhibitory action of miR-126 on the RhoA signaling pathway by coupling with Ga13, therefore validating that miR-126 acts as a tumor suppressor by inactivating RhoA signaling via the CXCR4/Ga13/RhoA axis in DSCs. 
It has been hypothesized that upregulating miR-126 can weaken the metastatic ability of HCC by suppressing the expression of LRP6, a Wnt co-receptor, and its downstream mediator $\beta$-catenin (51). This may be consistent with a study demonstrating that the activation of the $\mathrm{Wnt} / \beta$-catenin signaling pathway results in spontaneous HCC in farnesoide $\mathrm{X}$ receptor-knockout mice (76). In addition, activation of the $\mathrm{Wnt} / \beta$-catenin signaling pathway is involved in promoting EMT of GC cells (77) and numerous studies have confirmed that various miRNAs, including miR-544a, modulate EMT in GC via Wnt/ $\beta$-catenin signaling (78). Upregulation of RGS3 can enhance the pro-tumorigenic signals generated by the Wnt/ $\beta$-catenin pathway and induce EMT $(41,63)$. Therefore, miR-126 directly targeting and downregulating RGS3 is possibly involved in its inhibition of EMT via the Wnt/ $\beta$-catenin pathway (41). Furthermore, miR-126 functions as a tumor suppressor in ESCC via the ADAM9-EGFR-AKT axis and the downregulation of ADAM9 suppresses the activation of the EGFR-AKT pathway by restricting phosphorylation (26). In addition to the anti-tumor effects of miR-126 through the aforementioned signaling pathways, miR-126 also exhibits a pro-tumorigenic effect in DSCs. A pathway has been proposed in which miR-126 dysregulates SOX2, leading to overexpression of placenta-specific 1, a tumor suppressor for gastric adenocarcinoma; this pathway may serve a positive role in gastric carcinogenesis (33).

It is noteworthy that VEGF, VEGFR, EGFR and CXCR4 are pro-inflammatory factors that are frequently upregulated in the tumor microenvironment, possibly leading to oncogenic events (79). As aforementioned, the interactions between miR-126 and these cytokines or their receptors exert modulatory effects on several dysregulated pathways, including MAPK/ERK, AKT/mTOR and RhoA signaling pathways, which indicates a complicated cross-talk among cytokines, miRNAs and signaling pathways in tumorigenesis and tumor progression. Other miRNAs have also been reported to interact with cytokines in DSCs. For example, Ma et al (80) have demonstrated that interleukin (IL)-1 $\beta$-induced nuclear factor $\kappa$-light-chain-enhancer of activated $B$ cells activation results in increased miR-425 transcription, which further facilitates GC cell proliferation by suppressing phosphatase and tensin homolog.

\section{6. miR-126 serves as a useful biomarker in DSCs}

miRNAs exhibit several essential features of biomarkers, including an average length of 22 nucleotides, stable expression and ease of detection (81). Due to their ubiquitous and abnormal expression in human cancer types, they exhibit great potential as diagnostic and prognostic factors for cancer (82). As aforementioned, the dysregulation of several target genes due to aberrant expression of miR-126 is involved in DSCs, indicating the potential of miR-126 as a biomarker for this group of cancer types.

Previous studies have revealed that miR-126 is highly expressed in normal tissues compared with cancer tissues and DSC cell lines (Table I). Liu et al (25) identified 60 miRNAs, including miR-126, that were expressed differentially between matched EC and paracancerous normal tissues. Lower expression of miR-126 has been observed in both HCC tissues and liver cancer cells compared with normal controls $(16,51)$. In addition, higher levels of miR-126 can be used to discriminate HCC from metastatic adenocarcinoma in the liver along with other miRNAs (83). Hamada et al (56) demonstrated that miR-126 is significantly downregulated in invasive ductal adenocarcinoma (IDA) compared with normal pancreatic tissues, intraductal papillary mucinous adenoma and intraductal papillary mucinous carcinoma tissues. Furthermore, patients with IDA were revealed to exhibit more adverse outcomes compared with patients with intraductal papillary mucinous adenoma or intraductal papillary mucinous carcinoma due to a higher invasive potential (56). Similarly, other studies consider miR-126 as a representative of 21 dysregulated miRNAs when comparing PDAC with serous microcystic adenoma (57). Therefore, detecting the levels of miR-126 in tissues or cells may promote promising new strategies to diagnose DSCs.

Overwhelming evidence has indicated that miR-126 is associated with metastasis, cancer stage, tumor size or other clinicopathological characteristics of DSCs, in which metastasis is a leading cause of cancer-associated cases of mortality (84). Low expression of miR-126 is observed in metastatic CRC cell lines and miR-126 levels are significantly lower in patients with numerous metastatic sites compared with those with only one metastatic location $(48,85)$. Furthermore, the expression of miR-126 is negatively correlated with TNM stage and metastasis in patients with $\mathrm{CRC}$, indicating that lower expression levels of miR-126 may predict a poorer prognosis $(46,47)$. Low levels of miR-126 in tumors are similarly associated with lymph node metastasis, local invasion and TNM stage in GC, ESCC and other DSCs $(19,27,29)$. In addition, miR-126 may serve as an independent prognostic indicator for patients with ESCC (26). Li et al (86) established a seven-miRNA signature, with miR-126 designated as protective, to predict the relapse-free survival and overall survival of patients with GC. Similarly, miR-126 was identified as a predictor of venous metastases and survival of patients with $\mathrm{HCC}$ in a 20-miRNA prognostic signature (87). Dysregulation of miR-126 is inversely correlated with the clinicopathological parameters of HCC, including tumor size, tumor weight and alpha-fetoprotein (AFP) level, and is involved with tumor angiogenesis, microvascular invasion, tumor metastasis and early recurrence $(16,51,55)$. The gene targets of miR-126 may also exhibit a potential prognostic function. For example, downregulation of miR-126 and upregulation of CRK are synergistically correlated with tumor progression of GC and can therefore be a combined unfavorable prognostic factor for patients with GC (88). Consequently, timely detection of miR-126 and CRK levels may be of great importance in predicting the overall survival of patients with advanced GC (32).

In addition to the tissues, circulating miRNAs are also detected in plasma, which has been demonstrated to be a feasible method for diagnosing human cancer types (89). Previous studies have identified that the serum levels of miR-126 are altered in patients with CRC compared with healthy controls (90), and between patients with CRC with liver metastasis and those with localized CRC (89). Lower levels of miR-126 were also observed in the plasma of patients with PC compared with healthy individuals (91). Since serum 
miR-126 levels are significantly different between patients with HCC with hepatitis B virus (HBV-HCC) and their non-HCC counterparts, it is necessary to evaluate the plasma levels of miR-126 and AFP rather than AFP alone for diagnosing HBV-HCC (92).

However, several studies demonstrate ambiguous results regarding the role of miR-126 in DSC diagnosis. miR-126 has been identified as both a benign and an unfavorable prognostic factor. Overexpression of miR-126 accompanied with downregulation of CADM1 may function as an adverse factor for patients with stage I GC (38). While miR-126 demonstrates no association with the prognosis of patients with EC (24), it can act as an independent predictor of the outcome of ESCC (26).

\section{Therapeutic implications of miR-126 in DSCs}

miRNAs are promising therapeutic targets for various cancer types on account of their post-transcriptional regulation of numerous cancer-associated target genes (7). Therefore artificially modulating the expression levels of miRNAs and thereby their targets is a rational therapeutic approach. Accordingly, the inhibitory role of miR-126 in tumorigenesis and the development of DSCs could be exploited for treatment of these cancer types. Restoring the expression of miR-126 to influence different targets and pathways could be a novel therapeutic strategy for DSCs. Ectopic expression of miR-126 in CRC (47), GC (19,31), EC (29), HCC (51,52) and PAC (58) attenuates cell-cycle progression, suppresses tumor proliferation, oncogenesis, colony formation, invasion and metastasis, and simultaneously promotes tumor cell apoptosis. Increasing the expression of miR-126 in pancreatic benign cystic tumors prevents them developing into PC (57).

miRNAs have also been implicated in chemoresistance of cancer cells and failed chemotherapy; the miRNAs associated with apoptosis are usually responsible for this phenomenon (93). An association between miR-126 and chemoresistance in DSCs has been reported. A low level of miR-126 in primary CRC tumors is associated with lower sensitivity to oxaliplatin in metastatic CRC (85). In another study, upregulation of miR-126 significantly improved the sensitivity of colon cancer cells to oxaliplatin (50). Multiple studies have revealed lower expression of miR-126 in drug-resistant GC cell lines and re-sensitization to vincristine and adriamycin following ectopic expression of miR-126 (39). miR-126 may also affect the sensitivity of GC cells to cisplatin, which is one of the major chemotherapeutic options in treating patients with advanced GC (60). A previous study identified that miR-126 is downregulated along with a number of other miRNAs in hydroxycamptothecin-resistant GC cells (94). Therefore, another feasible therapeutic strategy is using synthetic miR-126 as a drug-sensitivity mediator in DSCs.

However, there are a number of limitations in the clinical application of miR-126, including delivery of the effector molecule to target sites, which is considered to be the major challenge for miRNA-based treatment (95). Stable nucleic acid lipid particles, polyethylene glycol or virus-like particles have been tested as carriers of miR-126 $(95,96)$. Additionally, another study investigated the possibility of using carcinoma cells targeting oncolytic adenovirus for delivery of
miR-126 (58). Despite the generally high efficacy of viral vectors, there are apprehensions regarding their toxicity and immunogenicity, which limit their clinical usage (97).

Recent studies have demonstrated that the dysregulation of miRNAs in cancer is associated with DNA methylation. Therefore, altering the methylation status of tumor-associated genes is a promising epigenetic therapy (98). Zhang et al (45) revealed that deficiency of miR-126 in CRC cells may be a result of aberrant DNA methylation, since miR-126 expression was restored following demethylation of CRC cells with 5-aza-2'-deoxycytidine. Similarly, miR-126 expression is regulated by the DNMT1-miR-126 epigenetic circuit in ESCC cells via hypermethylation of the EGFL7 promoter. Therefore, miR-126-associated epigenetic modification exhibits significant therapeutic potential in ESCC (26).

Since miRNAs exert their oncotherapeutic effects by regulating target genes, the direct regulation of target genes should be validated. Suppressing CRKL in GC cells had the same effects as overexpressing miR-126, including inducing cell cycle arrest at $\mathrm{G}_{0} / \mathrm{G}_{1}$ phase and inhibiting proliferation (34). Similarly, the therapeutic effect of inhibiting ESCC cell proliferation and migration can be acquired not only by the re-introduction of miR-126 but also dysregulation of ADAM9 (26). Furthermore, the miR-126/ADAM9 axis can be a therapeutic target in $\mathrm{PC}$ in terms of suppressing migration of tumor cells (56).

The heterogeneity of the miRNA regulation network makes the therapeutic role of miR-126 in DSCs controversial. It has been reported that decreasing but not increasing the expression of miR-126 may inhibit migration and invasion of GC cells (38). Another study hypothesized that a miR-126 inhibitor combined with TACE may achieve an improved therapeutic effect in HCC (53). In addition, the combination of miR-126 with other miRNAs, including miR-34a, targeting different genes could achieve improved results in PAC (58). Notably, overexpression of miR-126 destroyed cell viability, arrested cell cycle, inhibited clonogenicity and blocked tumorigenicity by targeting KRAS-associated genes in multiple KRAS-mutant CRC cells but not in KRAS-WT cancer cells (69).

\section{Conclusions}

The current review has summarized that miR-126 is a tumor suppressor and its low levels in DSC tissues are associated with tumor development and progression. Therefore, restoring or increasing miR-126 levels is a promising therapeutic strategy for DSCs. However, the difficulty in transporting miR-126 to target sites may be a limitation until safe and effective vectors are developed. In addition, the aberrant serum levels of miR-126 in patients with DSCs may serve as predictive or diagnostic biomarkers.

miR-126 can also act as an oncogene in specific DSCs. Regardless of its function, it exerts its modulatory effects via different target genes and regulatory pathways with associated functions. Considering the significance and complexity of miR-126 and its regulatory network in DSCs, it is essential to further investigate the role of miR-126 in the initiation and progression of different cancer types to identify potential clinical applications. 


\section{Acknowledgements}

The authors thank Dr Qiang Liu for assisting with the writing of the manuscript and Dr Tao Li for valuable discussions (both Department of Gastroenterology of the First Affiliated Hospital of Nanchang University, Nanchang, China).

\section{Funding}

The review was supported by funding from the National Science Foundation Grants of China (nos. 81160307 and 81560395), the Jiangxi Science \& Technology Pillar Program and the Science Foundation for Young Scholars of Jiangxi Province (grant no. 2007GQY1167).

\section{Availability of data and materials}

Not applicable.

\section{Authors' contributions}

MH wrote the manuscript. SX made the tables and diagrams. $\mathrm{QC}$, and SZ checked and revised the manuscript; XZ put forward the concept, and was responsible for the organization, revision and submission of this manuscript. All authors read and approved the final manuscript.

\section{Ethics approval and consent to participate}

Not applicable.

\section{Patient consent for publication}

Not applicable.

\section{Competing interests}

The authors declare that they have no competing interests.

\section{References}

1. Torre LA, Bray F, Siegel RL, Ferlay J, Lortet-Tieulent J and Jemal A: Global cancer statistics, 2012. CA Cancer J Clin 65: $87-108,2015$

2. Ferlay J, Soerjomataram I, Dikshit R, Eser S, Mathers C, Rebelo M, Parkin DM, Forman D and Bray F: Cancer incidence and mortality worldwide: Sources, methods and major patterns in GLOBOCAN 2012. Int J Cancer 136: E359-E386, 2015.

3. Hidalgo M: Pancreatic cancer. N Engl J Med 362: 1605-1617, 2010.

4. Zhang L, Huang J, Yang N, Greshock J, Megraw MS, Giannakakis A, Liang S, Naylor TL, Barchetti A, Ward MR, et al: MicroRNAs exhibit high frequency genomic alterations in human cancer. Proc Natl Acad Sci USA 103: 9136-9141, 2006.

5. Di Leva G, Garofalo M and Croce CM: MicroRNAs in cancer. Annu Rev Pathol 9: 287-314, 2014

6. Moretti F, Thermann R and Hentze MW: Mechanism of translational regulation by $\mathrm{miR}-2$ from sites in the 5 ' untranslated region or the open reading frame. RNA 16: 2493-2502, 2010.

7. Chen CZ: MicroRNAs as oncogenes and tumor suppressors. N Engl J Med 353: 1768-1771, 2005.

8. Zhang Z, Li Z, Li Y and Zang A: MicroRNA and signaling pathways in gastric cancer. Cancer Gene Ther 21: 305-316, 2014

9. Fish JE, Santoro MM, Morton SU, Yu S, Yeh RF, Wythe JD Ivey KN, Bruneau BG, Stainier DY and Srivastava D: miR-126 regulates angiogenic signaling and vascular integrity. Dev Cell 15: 272-284, 2008.
10. Wang S, Aurora AB, Johnson BA, Qi X, McAnally J, Hill JA, Richardson JA, Bassel-Duby R and Olson EN: The endothelial-specific microRNA miR-126 governs vascular integrity and angiogenesis. Dev Cell 15: 261-271, 2008.

11. Meister J and Schmidt MHH: miR-126 and miR-126*: New players in cancer. ScientificWorldJournal 10: 2090-2100, 2010.

12. Soncin F, Mattot V, Lionneton F, Spruyt N, Lepretre F, Begue A and Stehelin D: VE-statin, an endothelial repressor of smooth muscle cell migration. EMBO J 22: 5700-5711, 2003.

13. Parker LH, Schmidt M, Jin SW, Gray AM, Beis D, Pham T, Frantz G, Palmieri S, Hillan K, Stainier DY, et al: The endothelial-cell-derived secreted factor Egfl7 regulates vascular tube formation. Nature 428: 754-758, 2004.

14. Campagnolo L, Leahy A, Chitnis S, Koschnick S, Fitch MJ, Fallon JT, Loskutoff D, Taubman MB and Stuhlmann H: EGFL7 is a chemoattractant for endothelial cells and is up-regulated in angiogenesis and arterial injury. Am J Pathol 167: 275-284, 2005.

15. Morgenbesser SD, Dufault MR, Martin TB, Lim E, Callahan M, Weber W, Winter SF, McLaren RP, Richards B, Cook BP, et al: Characterization of EGFL7 expression and function in tumorigenesis and angiogenesis. Cancer Res 65 (Suppl 9): S1103, 2005.

16. Hu MH, Ma CY, Wang XM, Ye CD, Zhang GX, Chen L and Wang JG: MicroRNA-126 inhibits tumor proliferation and angiogenesis of hepatocellular carcinoma by down-regulating EGFL7 expression. Oncotarget 7: 66922-66934, 2016.

17. Harris TA, Yamakuchi M, Ferlito M, Mendell JT and Lowenstein CJ: MicroRNA-126 regulates endothelial expression of vascular cell adhesion molecule 1. Proc Natl Acad Sci USA 105: 1516-1521, 2008.

18. Tang ST, Wang F, Shao M, Wang Y and Zhu HQ: MicroRNA-126 suppresses inflammation in endothelial cells under hyperglycemic condition by targeting HMGB1. Vascul Pharmacol 88: 48-55, 2017

19. Feng R, Chen X, Yu Y, Su L, Yu B, Li J, Cai Q, Yan M, Liu B and Zhu Z: miR-126 functions as a tumour suppressor in human gastric cancer. Cancer Lett 298: 50-63, 2010.

20. Ebrahimi F, Gopalan V, Smith RA and Lam AK: miR-126 in human cancers: Clinical roles and current perspectives. Exp Mol Pathol 96: 98-107, 2014

21. Lu J, Getz G, Miska EA, Alvarez-Saavedra E, Lamb J, Peck D, Sweet-Cordero A, Ebert BL, Mak RH, Ferrando AA, et al: MicroRNA expression profiles classify human cancers. Nature 435: 834-838, 2005.

22. Landgraf P, Rusu M, Sheridan R, Sewer A, Iovino N, Aravin A, Pfeffer S, Rice A, Kamphorst AO, Landthaler M, et al: A mammalian microRNA expression atlas based on small RNA library sequencing. Cell 129: 1401-1414, 2007.

23. Lagos-Quintana M, Rauhut R, Yalcin A, Meyer J, Lendeckel W and Tuschl T: Identification of tissue-specific microRNAs from mouse. Curr Biol 12: 735-739, 2002.

24. Hu Y, Correa AM, Hoque A, Guan B, Ye F, Huang J, Swisher SG, Wu TT, Ajani JA and Xu XC: Prognostic significance of differentially expressed miRNAs in esophageal cancer. Int J Cancer 128: 132-143, 2011.

25. Liu SG, Qin XG, Zhao BS, Qi B, Yao WJ, Wang TY, Li HC and Wu XN: Differential expression of miRNAs in esophageal cancer tissue. Oncol Lett 5: 1639-1642, 2013.

26. Liu R, Gu J, Jiang P, Zheng Y, Liu X, Jiang X, Huang E, Xiong S, Xu F, Liu G, et al: DNMT1-microRNA126 epigenetic circuit contributes to esophageal squamous cell carcinoma growth via ADAM9-EGFR-AKT signaling. Clin Cancer Res 21: 854-863, 2015.

27. Li H, Meng F, Ma J, Yu Y, Hua X, Qin J and Li Y: Insulin receptor substrate-1 and Golgi phosphoprotein 3 are downstream targets of miR-126 in esophageal squamous cell carcinoma. Oncol Rep 32: 1225-1233, 2014.

28. Nie ZC, Weng WH, Li J, Xu YT and Li Z: Down-regulation of miR-126 in esophageal carcinoma tissues and its inhibition effect on proliferation and migration of esophageal carcinoma cell line EC109. Tumor 35: 55-64, 2015.

29. Nie ZC, Weng WH, Shang YS, Long Y, Li J, Xu YT and Li Z: MicroRNA-126 is down-regulated in human esophageal squamous cell carcinoma and inhibits the proliferation and migration in EC109 cell via PI3K/AKT signaling pathway. Int J Clin Exp Pathol 8: 4745-4754, 2015.

30. Kong R, Ma Y, Feng J, Li S, Zhang W, Jiang J, Zhang J, Qiao Z, Yang $X$ and Zhou B: The crucial role of miR-126 on suppressing progression of esophageal cancer by targeting VEGF-A. Cell Mol Biol Lett 21: 3,2016. 
31. Li X, Wang F and Qi Y: miR-126 inhibits the invasion of gastric cancer cell in part by targeting Crk. Eur Rev Med Pharmacol Sci 18: 2031-2037, 2014

32. Yue S, Shi H, Han J, Zhang T, Zhu W and Zhang D: Prognostic value of microRNA-126 and CRK expression in gastric cancer Onco Targets Ther 9: 6127-6135, 2016.

33. Otsubo T, Akiyama Y, Hashimoto Y, Shimada S, Goto K and Yuasa Y: MicroRNA-126 inhibits SOX2 expression and contributes to gastric carcinogenesis. PLoS One 6: e16617, 2011.

34. Wang J, Chen X, Li P, Su L, Yu B, Cai Q, Li J, Yu Y, Liu B and Zhu Z: CRKL promotes cell proliferation in gastric cancer and is negatively regulated by miR-126. Chem Biol Interact 206: 230-238, 2013

35. Chen H, Li L, Wang S, Lei Y, Ge Q, Lv N, Zhou X and Chen C: Reduced miR-126 expression facilitates angiogenesis of gastric cancer through its regulation on VEGF-A. Oncotarget 5: 11873-11885, 2014.

36. Liu LY, Wang W, Zhao LY, Guo B, Yang J, Zhao XG, Hou N, Ni L, Wang AY, Song TS, et al: Mir-126 inhibits growth of SGC-7901 cells by synergistically targeting the oncogenes PI3KR 2 and Crk, and the tumor suppressor PLK2. Int J Oncol 45: 1257-1265, 2014

37. Wang J, Chen X, Su L, Li P, Cai Q, Liu B, Wu W and Zhu Z: MicroRNA-126 inhibits cell proliferation in gastric cancer by targeting LAT-1. Biomed Pharmacother 72: 66-73, 2015.

38. Yang Z, Wang R, Zhang T and Dong X: MicroRNA-126 regulates migration and invasion of gastric cancer by targeting CADM1. Int J Clin Exp Pathol 8: 8869-8880, 2015.

39. Wang P, Li Z, Liu H, Zhou D, Fu A and Zhang E: MicroRNA-126 increases chemosensitivity in drug-resistant gastric cancer cells by targeting EZH2. Biochem Biophys Res Commun 479: 91-96, 2016.

40. Wang J, Zhou Y, Fei X, Chen X, Yan J, Liu B and Zhu Z: ADAM9 functions as a promoter of gastric cancer growth which is negatively and post-transcriptionally regulated by miR-126. Oncol Rep 37: 2033-2040, 2017.

41. Wang J,Zhou Y, Fei X, Chen X and Zhu Z: Regulator of G-protein signaling 3 targeted by miR-126 correlates with poor prognosis in gastric cancer patients. Anticancer Drugs 28: 161-169, 2017.

42. Banerjee N, Kim H, Talcott S and Mertens-Talcott S Pomegranate polyphenolics suppressed azoxymethane-induced colorectal aberrant crypt foci and inflammation: Possible role of miR-126/VCAM-1 and miR-126/PI3K/AKT/mTOR Carcinogenesis 34: 2814-2822, 2013.

43. Guo C, Sah JF, Beard L, Willson JK, Markowitz SD and Guda K: The noncoding RNA, miR-126, suppresses the growth of neoplastic cells by targeting phosphatidylinositol 3-kinase signaling and is frequently lost in colon cancers. Genes Chromosomes Cancer 47: 939-946, 2008.

44. Hansen TF, Andersen CL, Nielsen BS, Spindler KL, Sørensen FB Lindebjerg $\mathrm{J}$, Brandslund I and Jakobsen A: Elevated microRNA-126 is associated with high vascular endothelial growth factor receptor 2 expression levels and high microvessel density in colorectal cancer. Oncol Lett 2: 1101-1106, 2011.

45. Zhang Y, Wang X, Xu B, Wang B, Wang Z, Liang Y, Zhou J, $\mathrm{Hu} \mathrm{J}$ and Jiang B: Epigenetic silencing of miR-126 contributes to tumor invasion and angiogenesis in colorectal cancer. Oncol Rep 30: 1976-1984, 2013.

46. Yuan W, Guo YQ, Li XY, Deng MZ, Shen ZH, Bo CB, Dai YF, Huang MY, Yang ZY, Quan YS, et al: MicroRNA-126 inhibits colon cancer cell proliferation and invasion by targeting the chemokine (C-X-C motif) receptor 4 and Ras homolog gene family, member A, signaling pathway. Oncotarget 7 : 60230-60244, 2016

47. Liu Y, Zhou Y, Feng X, An P, Quan X, Wang H, Ye S, Yu C, He Y and Luo H: MicroRNA-126 functions as a tumor suppressor in colorectal cancer cells by targeting CXCR4 via the AKT and ERK1/2 signaling pathways. Int J Oncol 44: 203-210, 2014.

48. Li N, Tang A, Huang S, Li Z, Li X, Shen S, Ma J and Wang X: miR-126 suppresses colon cancer cell proliferation and invasion via inhibiting RhoA/ROCK signaling pathway. Mol Cell Biochem 380: 107-119, 2013.

49. Zhou Y, Feng X, Liu YL, Ye SC, Wang H, Tan WK, Tian T, Qiu YM and Luo HS: Down-regulation of miR-126 is associated with colorectal cancer cells proliferation, migration and invasion by targeting IRS-1 via the AKT and ERK1/2 signaling pathways. PLoS One 8: e81203, 2013.

50. Li N, Li X, Huang S, Shen S and Wang X: miR-126 inhibits colon cancer proliferation and invasion through targeting IRS1, SLC7A5 and TOM1 gene. Zhong Nan Da Xue Xue Bao Yi Xue Ban 38: 809-817, 2013 (In Chinese).
51. Du C, Lv Z, Cao L, Ding C, Gyabaah OA, Xie H, Zhou L, Wu J and Zheng S: miR-126-3p suppresses tumor metastasis and angiogenesis of hepatocellular carcinoma by targeting LRP6 and PIK3R2. J Transl Med 12: 259, 2014

52. Zhao C, Li Y, Zhang M, Yang Y and Chang L: miR-126 inhibits cell proliferation and induces cell apoptosis of hepatocellular carcinoma cells partially by targeting Sox 2 . Hum Cell 28: 91-99, 2015.

53. Ji JS, Xu M, Song JJ, Zhao ZW, Chen MJ, Chen WQ, Tu JF and Yang XM: Inhibition of microRNA-126 promotes the expression of Spred1 to inhibit angiogenesis in hepatocellular carcinoma after transcatheter arterial chemoembolization: In vivo study. Onco Targets Ther 9: 4357-4367, 2016.

54. Gong C, Fang J, Li G, Liu HH and Liu ZS: Effects of microRNA-126 on cell proliferation, apoptosis and tumor angiogenesis via the down-regulating ERK signaling pathway by targeting EGFL7 in hepatocellular carcinoma. Oncotarget 8: 52527-52542, 2017

55. Xiang LY, Ou HH, Liu XC, Chen ZJ, Li XH, Huang Y and Yang DH: Loss of tumor suppressor miR-126 contributes to the development of hepatitis B virus-related hepatocellular carcinoma metastasis through the upregulation of ADAM9. Tumor Biol 39: 1010428317709128, 2017.

56. Hamada S, Satoh K, Fujibuchi W, Hirota M, Kanno A, Unno J, Masamune A, Kikuta K, Kume K and Shimosegawa T: miR-126 acts as a tumor suppressor in pancreatic cancer cells via the regulation of ADAM9. Mol Cancer Res 10: 3-10, 2012.

57. Jiao LR, Frampton AE, Jacob J, Pellegrino L, Krell J, Giamas G, Tsim N, Vlavianos P, Cohen P, Ahmad R, et al: MicroRNAs targeting oncogenes are down-regulated in pancreatic malignant transformation from benign tumors. PLoS One 7: e32068, 2012.

58. Feng SD, Mao Z, Liu C, Nie YS, Sun B, Guo M and Su C: Simultaneous overexpression of miR-126 and miR-34a induces a superior antitumor efficacy in pancreatic adenocarcinoma. Onco Targets Ther 10: 5591-5604, 2017.

59. Pagano F, De Marinis E, Grignani F and Nervi C: Epigenetic role of miRNAs in normal and leukemic hematopoiesis. Epigenomics 5: 539-552, 2013.

60. Yan J, Dang Y, Liu S, Zhang Y and Zhang G: LncRNA HOTAIR promotes cisplatin resistance in gastric cancer by targeting miR-126 to activate the PI3K/AKT/MRP1 genes. Tumor Biol 37: $16345-16355,2016$

61. Wang XY, Wu MH, Liu F, Li Y, Li N, Li GY and Shen SR: Differential miRNA expression and their target genes between NGX6-positive and negative colon cancer cells. Mol Cell Biochem 345: 283-290, 2010 .

62. Wang JH, Chen XT, Wen ZS, Zheng M, Deng JM, Wang MZ, Lin HX, Chen K, Li J, Yun JP, et al: High expression of GOLPH3 in esophageal squamous cell carcinoma correlates with poor prognosis. PLoS One 7: e45622, 2012.

63. Shi CS, Huang NN and Kehrl JH: Regulator of G-protein signaling 3 isoform 1 (PDZ-RGS3) enhances canonical Wnt signaling and promotes epithelial mesenchymal transition. J Biol Chem 287: 33480-33487, 2012.

64. Singh SK, Chen NM, Hessmann E, Siveke J, Lahmann M, Singh G, Voelker N, Vogt S, Esposito I, Schmidt A, et al: Antithetical NFATc1-Sox2 and p53-miR200 signaling networks govern pancreatic cancer cell plasticity. EMBO J 34: 517-530, 2015.

65. Liu H, Wang S and Huang C: VEGFA+936C/T and $-634 \mathrm{G} / \mathrm{C}$ polymorphisms and gastric cancer risk: A meta-analysis. Asian Pac J Cancer Prev 12: 1979-1983, 2011.

66. Crawford M, Brawner E, Batte K, Yu L, Hunter MG, Otterson GA, Nuovo G, Marsh CB and Nana-Sinkam SP: MicroRNA-126 inhibits invasion in non-small cell lung carcinoma cell lines. Biochem Biophys Res Commun 373: 607-612, 2008.

67. Xiong Y, Kotian S, Zeiger MA, Zhang L and Kebebew E: miR-126-3p inhibits thyroid cancer cell growth and metastasis, and is associated with aggressive thyroid cancer. PLoS One 10: e0130496, 2015

68. Shi B, Sepp-Lorenzino L, Prisco M, Linsley P, deAngelis T and Baserga R: Micro RNA 145 targets the insulin receptor substrate- 1 and inhibits the growth of colon cancer cells. J Biol Chem 282: 32582-32590, 2007

69. Hara T, Jones MF, Subramanian M, Li XL, Ou O, Zhu Y, Yang Y, Wakefield LM, Hussain SP, Gaedcke J, et al: Selective targeting of KRAS-mutant cells by miR-126 through repression of multiple genes essential for the survival of KRAS-mutant cells. Oncotarget 5: 7635-7650, 2014 
70. Otsubo T, Akiyama Y, Yanagihara K and Yuasa Y: SOX2 is frequently downregulated in gastric cancers and inhibits cell growth through cell-cycle arrest and apoptosis. Br J Cancer 98: 824-831, 2008

71. Osaki M, Oshimura M and Ito H: PI3K-Akt pathway: Its functions and alterations in human cancer. Apoptosis 9: 667-676, 2004.

72. Okumura E, Fukuhara T, Yoshida H, Hanada Si S, Kozutsumi R, Mori M, Tachibana K and Kishimoto T: Akt inhibits Myt1 in the signalling pathway that leads to meiotic G2/M-phase transition. Nat Cell Biol 4: 111-116, 2002.

73. Xu WH, Zhang JB, Dang Z, Li X, Zhou T, Liu J, Wang DS, Song WJ and Dou KF: Long non-coding RNA URHC regulates cell proliferation and apoptosis via ZAK through the ERK/MAPK signaling pathway in hepatocellular carcinoma. Int J Biol Sci 10: 664-676, 2014.

74. Wang SC, Lin JK, Wang HS, Yang SH, Li AF and Chang SC: Nuclear expression of CXCR4 is associated with advanced colorectal cancer. Int J Colorectal Dis 25: 1185-1191, 2010.

75. Li Z, Li N, Wu M, Li X, Luo Z and Wang X: Expression of miR-126 suppresses migration and invasion of colon cancer cells by targeting CXCR4. Mol Cell Biochem 381: 233-242, 2013.

76. Wolfe A, Thomas A, Edwards G, Jaseja R, Guo GL and Apte U: Increased activation of the $\mathrm{Wnt} / \beta$-catenin pathway in spontaneous hepatocellular carcinoma observed in farnesoid $\mathrm{X}$ receptor knockout mice. J Pharmacol Exp Ther 338: 12-21, 2011.

77. Huang J, Xiao D, Li G, Ma J, Chen P, Yuan W, Hou F, Ge J, Zhong M, Tang Y, et al: EphA2 promotes epithelial-mesenchymal transition through the Wnt/ $\beta$-catenin pathway in gastric cancer cells. Oncogene 33: 2737-2747, 2014.

78. Yanaka Y, Muramatsu T, Uetake H, Kozaki K and Inazawa J: miR-544a induces epithelial-mesenchymal transition through the activation of WNT signaling pathway in gastric cancer. Carcinogenesis 36: 1363-1371, 2015 .

79. Germano G, Allavena P and Mantovani A: Cytokines as a key component of cancer-related inflammation. Cytokine 43 374-379, 2008

80. Ma J, Liu J, Wang Z, Gu X, Fan Y, Zhang W, Xu L, Zhang J and Cai D: NF-kappaB-dependent microRNA-425 upregulation promotes gastric cancer cell growth by targeting PTEN upon IL-1 $\beta$ induction. Mol Cancer 13: 40, 2014.

81. Sun Z, Meng C, Wang S, Zhou N, Guan M, Bai C, Lu S, Han Q and Zhao RC: MicroRNA-1246 enhances migration and invasion through CADM1 in hepatocellular carcinoma. BMC Cancer 14: 616, 2014.

82. Wang JL, Hu Y, Kong X, Wang ZH, Chen HY, Xu J and Fang JY: Candidate microRNA biomarkers in human gastric cancer: A systematic review and validation study. PLoS One 8: e73683, 2013.

83. Barshack I, Meiri E, Rosenwald S, Lebanony D, Bronfeld M, Aviel-Ronen S, Rosenblatt K, Polak-Charcon S, Leizerman I, Ezagouri M, et al: Differential diagnosis of hepatocellular carcinoma from metastatic tumors in the liver using microRNA expression. Int J Biochem Cell Biol 42: 1355-1362, 2010.

84. Fidler IJ: The pathogenesis of cancer metastasis: The 'seed and soil’ hypothesis revisited. Nat Rev Cancer 3: 453-458, 2003.
85. Hansen TF, Sørensen FB, Lindebjerg J and Jakobsen A: The predictive value of microRNA-126 in relation to first line treatment with capecitabine and oxaliplatin in patients with metastatic colorectal cancer. BMC Cancer 12: 83, 2012

86. Li X, Zhang Y, Zhang Y, Ding J, Wu K and Fan D: Survival prediction of gastric cancer by a seven-microRNA signature. Gut 59: 579-585, 2010.

87. Budhu A, Jia HL, Forgues M, Liu CG, Goldstein D, Lam A, Zanetti KA, Ye QH, Qin LX, Croce CM, et al: Identification of metastasis-related microRNAs in hepatocellular carcinoma. Hepatology 47: 897-907, 2008.

88. Feng R, Sah BK, Beeharry MK, Yuan F, Su L, Jin X, Yan M, Liu B, Li C and Zhu Z: Dysregulation of miR-126/Crk protein axis predicts poor prognosis in gastric cancer patients. Cancer Biomark 21: 335-343, 2018

89. Yin J, Bai Z, Song J, Yang Y, Wang J, Han W, Zhang J, Meng H, Ma X, Yang Y, et al: Differential expression of serum miR-126, miR-141 and miR-21 as novel biomarkers for early detection of liver metastasis in colorectal cancer. Chin J Cancer Res 26: 95-103, 2014

90. Li H, Zhang H, Lu G, Li Q, Gu J, Song Y, Gao S and Ding Y: Mechanism analysis of colorectal cancer according to the microRNA expression profile. Oncol Lett 12: 2329-2336, 2016.

91. Imamura T, Komatsu S, Ichikawa D, Miyamae M, Okajima W, Ohashi T, Kiuchi J, Nishibeppu K, Konishi H, Shiozaki A, et al: Depleted tumor suppressor miR-107 in plasma relates to tumor progression and is a novel therapeutic target in pancreatic cancer. Sci Rep 7: 5708, 2017.

92. Ghosh A, Ghosh A, Datta S, Dasgupta D, Das S, Ray S, Gupta S, Datta S, Chowdhury A, Chatterjee R, et al: Hepatic miR-126 is a potential plasma biomarker for detection of hepatitis $\mathrm{B}$ virus infected hepatocellular carcinoma. Int J Cancer 138: 2732-2744, 2016.

93. Zhou W, Yang W, Ma J, Zhang H, Li Z, Zhang L, Liu J, Han Z, Wang $H$ and Hong L: Role of miR-483 in digestive tract cancers: From basic research to clinical value. J Cancer 9: 407-414, 2018

94. Wu XM, Shao XQ, Meng XX, Zhang XN, Zhu L, Liu SX, Lin J and Xiao HS: Genome-wide analysis of microRNA and mRNA expression signatures in hydroxycamptothecin-resistant gastric cancer cells. Acta Pharmacol Sin 32: 259-269, 2011.

95. Borel F, Konstantinova P and Jansen PL: Diagnostic and therapeutic potential of miRNA signatures in patients with hepatocellular carcinoma. J Hepatol 56: 1371-1383, 2012

96. Liang G, Zhu Y, Jing A, Wang J, Hu F, Feng W, Xiao Z and Chen B: Cationic microRNA-delivering nanocarriers for efficient treatment of colon carcinoma in xenograft model. Gene Ther 23: 829-838, 2016

97. Zhang Y, Wang Z and Gemeinhart RA: Progress in microRNA delivery. J Control Release 172: 962-974, 2013.

98. Li XM, Wang AM, Zhang J and Yi H: Down-regulation of miR-126 expression in colorectal cancer and its clinical significance. Med Oncol 28: 1054-1057, 2011.

(7) $\Theta$ This work is licensed under a Creative Commons Attribution-NonCommercial-NoDerivatives 4.0 International (CC BY-NC-ND 4.0) License. 